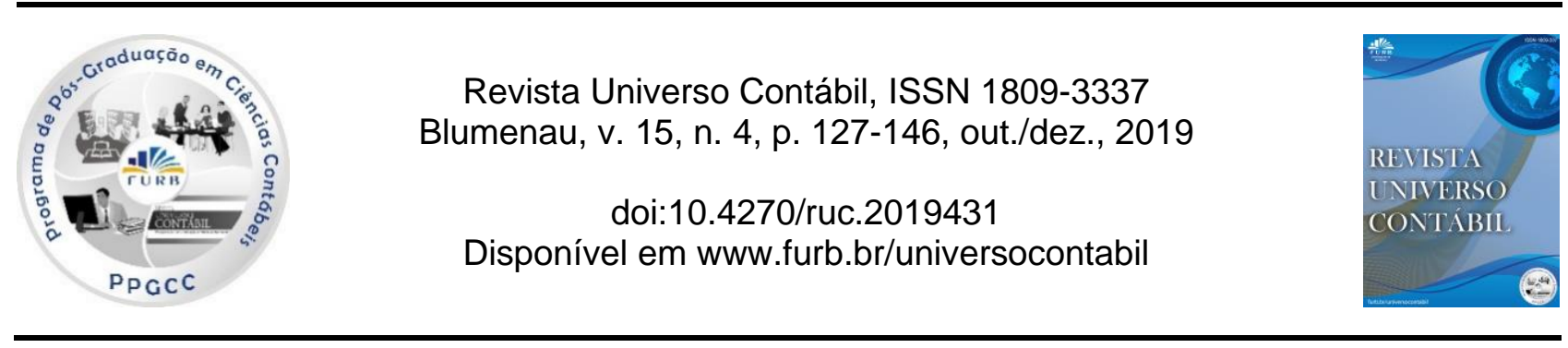

\title{
INCERTEZA DE MERCADO E O DESEMPENHO DE FUNDOS DE INVESTIMENTOS EM AÇÕES NO BRASIL
}

\section{MARKET UNCERTAINTY AND PERFORMANCE OF EQUITY MUTUAL FUNDS IN BRAZIL \\ INCERTIDUMBRE DEL MERCADO Y RENDIMIENTO DE LOS FONDOS DE INVERSIÓN EM ACCIONES EN BRASIL}

Recebido em: 18-09-2019

Avaliado em: 21-09-2020

Reformulado em: 12-10-2020

Aceito para publicação em: 27-10-2020

Publicado em: 20-12-2020

Editor Responsável: Tarcísio Pedro da Silva

Renê Coppe Pimentel ${ }^{1}$

Victoria Bossan $^{2}$

\section{RESUMO}

Este artigo analisa a relação entre a incerteza de mercado e performance dos fundos de investimento em ações no Brasil. Utilizando uma amostra abrangente e representativa, composta por 1.243 fundos, entre 1996 e 2019 (125.066 observações), os resultados documentam uma relação negativa e estatisticamente significativa entre performance dos fundos e incerteza de mercado, ou seja, períodos de maior incerteza estão associados a menor performance dos fundos. Também foi verificado que o tamanho do fundo, a existência de taxa de performance e a utilização de estratégias alavancadas de investimento estão positivamente associados com a performance dos fundos. Finalmente, são documentadas relações incrementais, positivas e significativas entre tamanho do fundo e perfil de risco na associação entre performance e incerteza de mercado. Ou seja, em momentos de incerteza, fundos com melhores performances são aqueles que possuem maior porte e mantêm perfis de riscos mais elevados, sugerindo maior habilidade dos gestores, maiores condições potenciais de ganho de escala e melhor retorno em função do risco assumido.

Palavras-chave: Fundos de investimento; Mercado de capitais; Desempenho; Retorno de ações.

\section{ABSTRACT}

This article analyses the relationship between market uncertainty and performance of equity mutual funds in Brazil. Using a comprehensive and representative sample of 1,243 funds between 1996 and 2019 (125,066 observations), the results document a negative and statistically significant relationship between fund performance and market uncertainty. In other words, periods of higher uncertainty are associated with lower performance. It was also found that the size of the fund, the existence of a performance fee and the use of leveraged investment strategies are positively associated with fund performance. Finally, positive, significant and incremental relationships between fund size and risk profile in the association between performance and market uncertainty

\footnotetext{
${ }^{1}$ Doutor em Controladoria e Contabilidade pela Universidade de São Paulo (USP); Professor do Departamento de Contabilidade da Universidade de São Paulo; E-mail: renecp@usp.br

${ }^{2}$ Graduação em Ciências Contábeis pela Universidade de São Paulo (USP); E-mail: victoria.bossan@usp.br
} 
are documented. That is, in times of uncertainty, mutual funds with better performances are those that are larger and maintain higher risk profiles, suggesting greater skill of managers, greater gain of scale and better return due to the risk taken.

Keywords: Investment funds; Capital markets; Performance; Stock return.

\section{RESUMEN}

Este artículo analiza la relación entre la incertidumbre del mercado y el rendimiento de los fondos de inversión de capital en Brasil. Utilizando una muestra exhaustiva y representativa de 1,243 fondos entre 1996 y 2019 (125,066 observaciones), los resultados documentan una relación negativa y estadísticamente significativa entre el rendimiento del fondo y la incertidumbre del mercado, es decir, los períodos de mayor incertidumbre están asociados con un menor rendimiento. También se descubrió que el tamaño del fondo, la existencia de una tasa de rendimiento y el uso de estrategias de inversión apalancadas se asocian positivamente con el rendimiento del fondo. Finalmente, se documentan las relaciones positivas, significativas e incrementales entre el tamaño del fondo y el perfil de riesgo en la asociación entre el rendimiento y la incertidumbre del mercado. Es decir, en tiempos de incertidumbre, los fondos con mejor desempeño son aquellos que son más grandes y mantienen perfiles de riesgo más altos, sugiriendo mayor habilidad de los administradores, mayores condiciones potenciales de ganancia de escala y mejor retorno por el riesgo asumido.

Palabras-clave: Fondos de Inversión; Mercado de capitales; Rendimiento; Devolución de acciones.

\section{INTRODUÇÃO}

Nas últimas décadas, a gestão de recursos financeiros por meio de fundos de investimento vem ganhando relevância cada vez maior no cenário internacional, assim como aumenta a relevância da eficiência dos gestores na geração de performances atrativas para investidores (Gârleanu \& Pedersen, 2018). No Brasil, desde a implantação das medidas econômicas e relativa estabilidade monetária trazidas pelo Plano Real, em 1994, o cenário econômico local passou por significativas alterações. $\mathrm{O}$ crescimento econômico, aliado à relativa estabilidade monetária, criou um ambiente favorável à crescente indústria de fundos de investimentos (Borges \& Martelanc, 2015).

Espera-se que os fundos geridos por profissionais e que contam com ganhos de escala nas atividades de investimento superem seus benchmarks de performance. No entanto, evidências empíricas mostram que a grande maioria dos fundos não remuneram adequadamente seus cotistas e não superam seus benchmarks (Harvey \& Liu, 2019). Da mesma forma, espera-se que fundos de maior risco tragam retornos mais elevados, o que nem sempre é verificado na prática (Duanmu, Malakhov, \& Mccumber, 2018). Especificamente, tratando-se de fundos de ações, a expectativa é que tais fundos superem o índice de mercado de ações local (ou global), uma vez que tal índice é utilizado como benchmark, gerando maiores ganhos ao investidor.

Lambert e Platania (2020), Wang e Zheng (2018), Bali, Brown, e Caglayan (2014), Kosowski (2011) e Ferson e Schadt (1996), por exemplo, mostram que a performance dos fundos de investimentos pode variar de forma dinâmica em função da situação de mercado como um todo, podendo afetar significativamente a tomada de decisão e retorno dos investidores. Um dos aspectos documentados na literatura que está associado à redução da alocação eficiente de recursos e da capacidade dos agentes do mercado em estimar a performance futura das empresas é a incerteza de mercado (Amiram et al, 2018; Hope \& Kang, 2005). Segundo Jurado, Ludvigson e Ng (2015), a incerteza de mercado pode impossibilitar aos gestores a alocação ótima de recursos e a antecipação dos movimentos macroeconômicos. 
Nesse sentido, Racicot e Theoret (2016) documentam que a incerteza de mercado é capaz de concentrar a negociação de ativos em alguns grupos de empresas menos arriscadas e, portanto, com menores níveis de retorno. Assim, gestores dos fundos de investimentos reduzem a tomada de risco em momentos de maior incerteza macroeconômica o que torna as estratégias dos diversos fundos mais homogêneas e com menores performances em relação a períodos de menor incerteza.

O objetivo deste artigo é, portanto, analisar se há relação entre a incerteza de mercado e performance dos fundos de investimento em ações no Brasil. Adicionalmente, busca-se avaliar se há relação incremental do tamanho e do nível de risco assumido em momentos de incerteza na performance dos fundos. Para tanto, utiliza-se uma amostra abrangente e representativa, composta por 1.243 fundos de investimento em ações, durante o período de 1996 a março de 2019, resultando em 125.066 observações. Para avaliação da performance dos fundos de investimento, utiliza-se a medida de alfa de Jensen (Jensen, 1969), amplamente utilizada na literatura da área. Evidência recente em Agarwal, Green e Ren (2018) mostra que a medida de performance com alfas obtidos a partir do modelo CAPM (Capital Asset Pricing Model) explica melhor o comportamento de fundos de investimento do que modelos mais sofisticados. A medida de incerteza de mercado é (MU, market uncertainty) é baseada na volatilidade diária dos preços dos ativos em determinado período (Amiram et al., 2018; Jurado, Ludvigson, \& Ng, 2015)

Os resultados documentam uma relação negativa e estatisticamente significativa entre performance dos fundos e incerteza de mercado, ou seja, períodos de maior incerteza estão associados a menores performance dos fundos. Também se verificou de forma consistente que, em média, o tamanho do fundo de investimento, a existência de taxa de performance pelo gestor e a utilização de estratégias alavancadas de investimento estão positivamente associados com a performance dos fundos. Finalmente, são documentadas relações incrementais, positivas e significativas entre tamanho do fundo e perfil de risco na associação entre performance e incerteza de mercado. Ou seja, fundos maiores possuem performance superior aos fundos menores em momentos de maiores níveis de incerteza, sugerindo maior habilidade dos gestores conforme sugere Borges e Materlanc (2015) e maiores condições potenciais de ganho de escala nas negociações, conforme sugere Elton, Gruber e Blake (2012). Já em relação ao risco, o presente estudo mostra que períodos de maior incerteza estão associados a maior concentração da negociação em ativos com menores níveis de risco, e, consequentemente, de menores retornos, conforme sugerem Racicot e Theoret (2016). Assim, fundos que mantêm perfil de risco elevando durante momentos de incerteza tendem a obter, em média, performance superior aos menos expostos a riscos.

No Brasil, apesar de a literatura sobre fundos ser ampla, os achados empíricos são conflitantes. Alguns estudos identificam que fundos de ações e multimercados teriam desempenho superior ao do mercado (Guzella \& Campani, 2017) e que fundos com melhor desempenho apresentam grande persistência de retorno (Matos \& Nave, 2012). Outros estudos documentam que, em média, no Brasil, os fundos não geram retornos anormais/extraordinários (Malaquias, \& Eid, 2013) ou que apenas poucos fundos fazem, sendo que tais retornos não são persistentes (Gomes, \& Cresto, 2010), ou ainda, que gestores de fundos não apresentam habilidades especiais para geração de retornos anormais (Casaccia et al., 2011).

$\mathrm{O}$ artigo contribui com a literatura sobre performance de fundos de investimento no Brasil ao explicar a variação da performance dos fundos de investimento em ações com base na incerteza de mercado de cada período. Tais resultados são substancialmente relevantes em mercados emergentes em que o ambiente macroeconômico é caracterizado por grandes níveis de incerteza quando comparados a mercados menos voláteis. Os achados são, portanto, potencialmente úteis a profissionais tais como investidores, gestores de recursos, analistas de investimentos, reguladores e acadêmicos, que amplamente analisaram o tema sem, no entanto, analisar o desempenho de fundos como uma função temporal da incerteza de mercado.

O restante do artigo está estruturado como segue: na Seção 2, é feita revisão da literatura de interesse e formulação das hipóteses. A Seção 3 apresenta e descreve a amostra, desenho de 
pesquisa e variáveis de interesse. A Seção 4 apresenta as principais análises, resultados e análises adicionais. A Seção 5 apresenta as considerações finais.

\section{FUNDAMENTAÇÃO TEÓRICA E FORMULAÇÃO DAS HIPÓTESES}

No Brasil, os fundos de investimento são regulados e registrados na Comissão de Valores Mobiliários (CVM). A criação do fundo cabe a um administrador, usualmente uma instituição financeira, responsável por definir os objetivos, políticas de investimento, categorias de ativos financeiros para composição da carteira, taxas a serem cobradas e demais regras de funcionamento do fundo.

O presente trabalho analisa os fundos de investimentos em ações que, conforme a Instrução CVM No555/14 "devem ter como principal fator de risco a variação de preços de ações admitidas à negociação no mercado organizado". No mínimo $67 \%$ do patrimônio líquido destes fundos deve ser composto por ações negociadas em mercados organizados; bônus ou recibos de subscrição e certificados de depósito de ação também negociados em mercados organizados; cotas de fundos de ações ou Brazilian Depositary Receipts classificados como nível II e III. Os recursos da carteira que excederem podem ser aplicados em quaisquer outras modalidades de ativos financeiros, respeitados os limites impostos pelo art. 103 da mesma Instrução.

De maneira geral, a literatura internacional e nacional em finanças explora substancialmente o tema 'fundos de investimento' (aqui incluídos uma série de abordagens distintas como fundos de ações, multimercado, renda fixa, cambial etc. e seus equivalentes no exterior, tais como hedge funds).

A alocação de recursos implementada por gestores dos fundos de investimentos e suas respectivas performances são impactadas por a situações sistêmicas do mercado (Sun, Wang, \& Zheng, 2018). Por exemplo, em relação à volatilidade de mercado, Billio, Sherman e Pelizzon (2010) constatam que alta volatilidade associada a crises financeiras faz com que fundos de investimento apresentem maior exposição a riscos, sugerindo que risco de liquidez e risco de crédito são fatores que afetam a performance dos fundos de investimento em períodos econômicos desfavoráveis (crises). Por sua vez, Boyson, Stahel e Stulz (2010) documentam efeito contágio de fundos devido a variações de liquidez de mercado.

Chen e Liang (2007) documentam que os fundos de investimentos antecipam variações na volatilidade de mercado, nos retornos dos fundos e sua combinação. Já Cao, Simin e Wang (2013) identificam que gestores de fundos têm a capacidade de antecipar mudanças na liquidez de mercado. Finalmente, Bali et al. (2014) mostram que uma proporção substancial da variação nos retornos dos fundos de investimento pode ser explicada por vários fatores de risco macroeconômicos.

Fung et al. (2008) analisam se o alfa dos fundos variou ao longo do tempo em fundos que entregam alfa e fundos que entregam beta e documentam que fundos com alfas positivos são menos prováveis de serem liquidados (extintos), apresentam maior propensão a entregar alfa continuamente e recebem maiores fluxos de capital. Elton, Gruber e Blake (2012), por sua vez, buscaram analisar a influência do tamanho dos fundos em sua performance e mostram que despesas e taxas de gestão são menores para fundos de maior patrimônio líquido e diminuem conforme o tamanho do fundo aumenta ou sua performance melhora.

Similarmente, no Brasil, a literatura de Finanças traz diversos aspectos pelos quais o desempenho de fundos de investimentos pode ser analisado. Uma primeira vertente de pesquisa compara o desempenho a partir da relação risco x retorno. Utilizando análise por envoltório de dados, Ceretta e Costa Jr. (2001) identificaram que, dos 106 fundos mútuos de investimentos analisados, apenas sete foram considerados eficientes pois possuíam uma justa relação entre atributos desejáveis e indesejáveis além de contarem com atributos insuperáveis por quaisquer outros fundos da amostra. Já Varga (2001) compara diversos indicadores de performance (taxa de 
retorno realizada, índice de Sharpe, índice de Treynor, índice de Jensen e o indicador $\mathrm{M}^{2}$ ), e documenta que o índice de Treynor foi considerado o melhor na avaliação da adição de um fundo a uma carteira com vários fundos, uma vez que divide o excesso de retorno pelo risco sistemático. Castro e Minardi (2009) observaram que apenas um pequeno percentual de fundos é capaz de superar os índices de mercado e de ser bem sucedido ao explorar a estratégia do market timing. Concluíram, também, que maiores fundos geram maiores ganhos anormais.

Uma segunda linha de pesquisa avalia o desempenho de um fundo sob a ótica da eficiência administrativa. Usualmente, cobra-se uma taxa de administração para remunerar o administrador do fundo, bem como os prestadores de serviços, obtida de um percentual aplicado sobre o patrimônio líquido do fundo e apropriada diariamente. Em alguns casos há, ainda, a cobrança da taxa de performance, que pode variar de acordo com o desempenho do fundo. Dessa forma, Paulo e Itosu (2012), analisando 121 fundos multimercados, concluíram que não existe correlação entre a taxa de performance cobrada e o desempenho dos fundos, uma vez que as taxas de performance são baseadas majoritariamente na diferença obtida entre a rentabilidade do fundo e o retorno de determinado benchmark.

Uma terceira perspectiva de análise do desempenho dos fundos é baseada na estratégia de gestão das carteiras na forma ativa e passiva, em que os resultados são conflitantes. Faria, Souza e Malaquias (2016) e Castro e Minardi (2009) buscaram verificar em seu estudo se os fundos brasileiros de gestão ativa e passiva têm desempenho semelhante e os resultados mostram que o retorno médio dos fundos de gestão ativa não foi superior aos fundos de gestão passiva, apesar de adotarem estratégias de maior risco. De forma similar, porém com resultados diversos, Malacrida et al. (2006) constataram que os desempenhos dos fundos de renda variável apresentam resultados superiores quando considerados períodos mais longos. Os resultados corroboram a hipótese de gestão ativa no longo prazo, onde existem gestores capazes de obter ganhos extraordinários. Em estudo recente Silva, Roma e Iquiapaza (2020) documentam que gestores de carteiras ativas estão sendo capazes de aproveitar momentos de mispricing no mercado e que esses realizam mais negociações em busca de rentabilidade superior.

Ainda na relação entre fundos ativos e passivos, Ceretta e Milani (2012) analisam o impacto da oscilação e do tamanho do patrimônio líquido dos fundos brasileiros de ações e a influência de sua evolução etária sobre seus retornos. Os autores observam que o retorno dos fundos em um dado período não acompanhava a variação de seu patrimônio líquido no mesmo período e no período antecedente, de modo que o patrimônio existente não afeta o retorno de maneira imediata. Observou-se também que conforme um fundo envelhece, seu excesso de retorno diminui. Ao analisar os quartis de fundos ativos, verificou-se que o coeficiente alfa foi significativo para todos os quartis, além de aumentar progressivamente conforme se analisava quartis com patrimônios líquidos crescentes. Já para os fundos passivos, somente os quartis com fundos de patrimônio líquido maior apresentaram alfa significativo. Tal tendência de fundos com patrimônio líquido maior apresentarem melhor performance está em linha com estudos anteriores realizados na literatura brasileira.

Com base em evidências empíricas amplamente disponíveis na literatura, é esperado que a performance dos fundos de investimento em ações varie dinamicamente em função de condições sistêmicas do ambiente econômico (Lambert \& Platania, 2020; Wang \& Zheng, 2018; Bali, Brown, \& Caglayan, 2014; Kosowski, 2011; Sun, Otten, \& Bams, 2004; Ferson \& Schadt, 1996). Especificamente, o estudo seminal de Ferson e Schadt (1996, p.158) mostra que a performance dos fundos de investimento deve ser analisada em função de informações sobre o cenário econômico disponível e, em função disso, análises empíricas deveriam buscar avaliar tal desempenho de forma a "incorporar variáveis com informações públicas".

Em função disso, muitos estudos sequentes buscaram analisar elementos associados a performance dos fundos de investimento, seja em, por exemplo, cenários econômicos de expansão e retração (Kosowski, 2011), em função de sentimento de mercado (Zheng, Osmer, \& Zhang, 2018) 
ou em função do conhecimento acumulado por gestores dos fundos de investimento ao longo do tempo (Cai, Cheng, \& Yan, 2018).

Complementarmente, um dos aspectos documentados na literatura que está associado à redução da capacidade dos agentes do mercado em estimar a performance futura das empresas é a incerteza de mercado (Amiram et al, 2018; Hope \& Kang, 2005), que pode impossibilitar aos gestores a alocação ótima de recursos e a antecipação dos movimentos macroeconômicos (Jurado, Ludvigson, \& Ng, 2015), bem como concentrar a negociação de ativos em alguns grupos de empresas menos arriscadas, e portanto com menores níveis de retorno (Racicot \& Theoret, 2016). Nesse sentido, Racicot e Theoret (2016) documentam que fundos de investimentos reduzem a tomada de risco em momentos de maior incerteza macroeconômica o que torna as estratégias dos diversos fundos mais homogêneas e com menores performances em relação a períodos de menor incerteza. Assim, a primeira hipótese de pesquisa deste artigo é:

H1: A performance dos fundos de investimento em ações está negativamente relacionada com a incerteza de mercado em determinado período.

Da mesma forma, conforme amplamente identificadas na literatura associações significativas entre performance, tamanho e perfil de risco dos fundos, espera-se que haja relações incrementais, positivas e significativas entre tamanho do fundo e perfil de risco na associação entre performance e incerteza de mercado. A literatura documentou que fundos maiores possuem performance superior aos fundos menores, por exemplo, Borges e Materlanc (2015) mostram que os gestores de fundos grandes possuem habilidade para gerar retornos anormais positivos maiores que a média dos demais fundos. Já Elton, Gruber e Blake (2012) argumentam que o tamanho dos fundos pode gerar ganhos de escala e redução nos custos de gestão, o que pode favorecer o retorno final als cotistas. Nesse sentido, é possível esperar que, por serem maiores alguns fundos podem contar potencialmente com maior habilidade dos gestores e ganhos de escala, apresentar maiores performances incrementais em momentos de maiores incertezas, o que gera a a segunda hipótese de pesquisa:

H2: Fundos de investimento em ações de maior porte possuem performance superior aos fundos menores em momentos de maiores incertezas.

Como mencionado anteriormente, estudos recentes indicam que, em momentos de incerteza, gestores tende a concentrar a negociação de ativos em alguns grupos de empresas menos arriscadas e, portanto, com menores níveis de retorno (Lambert, \& Platania, 2020; Racicot, \& Theoret, 2016), o que estaria associado a uma redução sistemática nas taxas de performance dos fundos. Nesse sentido, é possivel esparar que fundos com perfil de risco mais agressivos tendem a marter maiores níveis de retorno e, potanto, performance superior aos menos expostos em momentos de maiores incertezas. Assim, a terceira hipótese de pesquisa é de que:

H3: Fundos de investimento em ações de maior com maior perfil de risco possuem performance superior aos fundos menor perfil de risco em momentos de maiores incertezas.

\section{AMOSTRA, MODELO EMPÍRICO E VARIÁVEIS}

\subsection{Base de dados e amostra}

Para o desenvolvimento da análise foram abordados aspectos qualitativos e quantitativos, a fim de se chegar a um panorama completo a respeito do desempenho dos fundos no período estudado. A base de dados utilizada foi obtida junto ao software Economatica e continha, a princípio, 1598 fundos de investimentos em ações, divididos nas seguintes categorias: Ações Livre, 
Valor/Crescimento, SmallCaps, Dividendos, Indexados, Índice Ativo, Setoriais e Sustentabilidade/Governança. As características quantitativas observadas foram obtidas a partir do valor da cota mensal, em reais, do patrimônio líquido dos fundos, da idade dos fundos, da média do Ibovespa no período e do CDI ao mês do período, obtido junto ao Banco Central do Brasil. Já os aspectos qualitativos foram analisados com base no indicador de desempenho e cobrança de taxa de performance.

$\mathrm{Da}$ amostra inicial, foram retirados os fundos que continham menos de 24 observações mensais, para que fosse possível a análise da evolução histórica do desempenho. Fundos de Ações com Investimentos no Exterior não foram considerados na amostra, uma vez que efeitos de taxas cambiais e mercados estrangeiros não fazem parte do objeto de estudo do artigo. A amostra final compreende 1.243 fundos, no período de janeiro de 1996 a março de 2019, resultando em 125.066 observações iniciais de cotas.

\subsection{Cálculo dos retornos, alfas e betas}

Para cada um dos fundos em análise, foram obtidos os retornos mensais a partir do logaritmo natural (LN) da divisão da cota atual pela cota do mês anterior: $R_{i t}=\ln \left(Q_{i t} / Q_{i t-1}\right)$, onde $Q_{i t}$ é a cota de fechamento (último dia útil do mês) do fundo $i$ no mês $t$. O mesmo procedimento foi feito para o cálculo da rentabilidade do índice Ibovespa, utilizado como proxy de mercado, $R_{m}$. Com os dados de retorno dos fundos e do mercado, tomou-se como base o modelo de CAPM, proposto por Jensen (1968), para o cálculo das medidas alfa de Jensen e beta, representado pela equação a seguir:

$$
R_{i t}-R_{f t}=\alpha_{i t}+\beta_{i t}\left(R_{m t}-R_{f t}\right)+\varepsilon_{i t}
$$

Onde $R_{i t}$ é o retorno do fundo $i$ no mês $t, R_{f t}$ é o retorno de um ativo livre de risco, medido pela taxa mensal do CDI no mês $t, R_{m t}$ é o retorno de um portfólio diversificado de mercado medido pelo Ibovespa no mês $t$ e eit representa o termo de erro. O intercepto do modelo, $\alpha_{i t}$, representa o alfa de Jensen, a inclinação da reta e $\beta_{i t}$ a exposição de risco do fundo em relação ao portfólio de mercado. $\mathrm{O}$ alfa de Jensen é uma medida de performance do fundo em relação ao ativo livre de risco, que explica melhor o comportamento de fundos de investimento do que modelos mais sofisticados (Agarwal, Green, \& Ren, 2018). "Em equilíbrio o CAPM postula que o alfa de qualquer ativo ou fundo deve ser igual a zero" (Varga, 2001, p.229) valores superiores a zero sugerem maior habilidade dos gestores em produzir retornos superiores à média de mercado (ou retornos.

O beta, coeficiente angular da equação, reflete uma medida de sensibilidade do retorno do fundo em relação a um índice de mercado, neste caso, o Ibovespa. As análises posteriores fazem uso de alfa e beta a fim de detalhar o desempenho dos fundos.

Costa, Blank, Oliveira e Villalobos (2019) e Otten e Bams (2004) argumentam que assumir que as medidas de performance dos fundos variam dinamicamente no tempo traz benefícios superiores à discriminação de fundos de investimento e possibilita a introdução de fatores dinâmicos de risco. Nesse sentido, este artigo estima a Equação 1 de forma a obter $\alpha$ e $\beta$ variando no tempo, ou seja, a performance do fundo variando de forma dinâmica em função do portfólio de mercado. Para tanto, a equação foi estimada por meio do método dos mínimos quadrados ordinários (OLS) para cada um dos meses $t$, utilizando-se informações históricas de um período móvel de 24 meses anteriores a $t$.

\subsection{Incerteza de mercado}

A medida para incerteza de mercado (MU, market uncertainty) é baseada na literatura anterior e considera a volatilidade diária dos preços dos ativos em determinado período (Amiram et 
al., 2018; Jurado, Ludvigson, \& $\mathrm{Ng}$, 2015), indicando que quanto maior a volatilidade, maior a incerteza percebida pelos agentes de mercado sobre o futuro da econômica especialmente em mercados emergentes (Hope \& Kang, 2005). Para tanto, utilizou-se os desvios padrões dos retornos diários do Ibovespa imediatamente ao fechamento do mês $t$. Foram utilizadas medidas alternativas para cálculo da incerteza de mercado por meio da variação dos períodos de observação ao se considerar os desvios padrões de 30, 60, 90 e 120 dias antes do fechamento do mês $t$. (Amiram et al., 2018).

A Figura 1, apresenta o comportamento das medidas de incerteza de mercado (MU) com base nos quatro períodos de variação de retorno (de 30 a 120 dias). Em geral, as medidas apresentam consistências em relação ao seu comportamento histórico, porém, é naturalmente perceptível que os desvios padrões são mais acentuados em períodos mais curtos (30 dias) e, consequentemente, é reduzido quando o período de cálculo é ampliado, como esperado. Nota-se que os períodos de maior volatilidade são aqueles ocorrem em 1999 (com a crise internacional causada pelos tigres asiáticos e da Argentina) e em 2008 (com a crise internacional iniciada com os títulos 'subprime' americanos). Adicionalmente, percebe-se diversos ciclos menores (mais curtos) em períodos eleitorais e crises políticas (como em 2015 e 2016). De maneira geral, percebe-se uma tendência de redução de longo prazo na volatilidade de mercado. Como será visto ao longo do artigo, a opção por um ou outro período de cálculo não muda qualitativamente os resultados obtidos.

Figura 1 - Série temporal diária da medida de incerteza de mercado (MU)

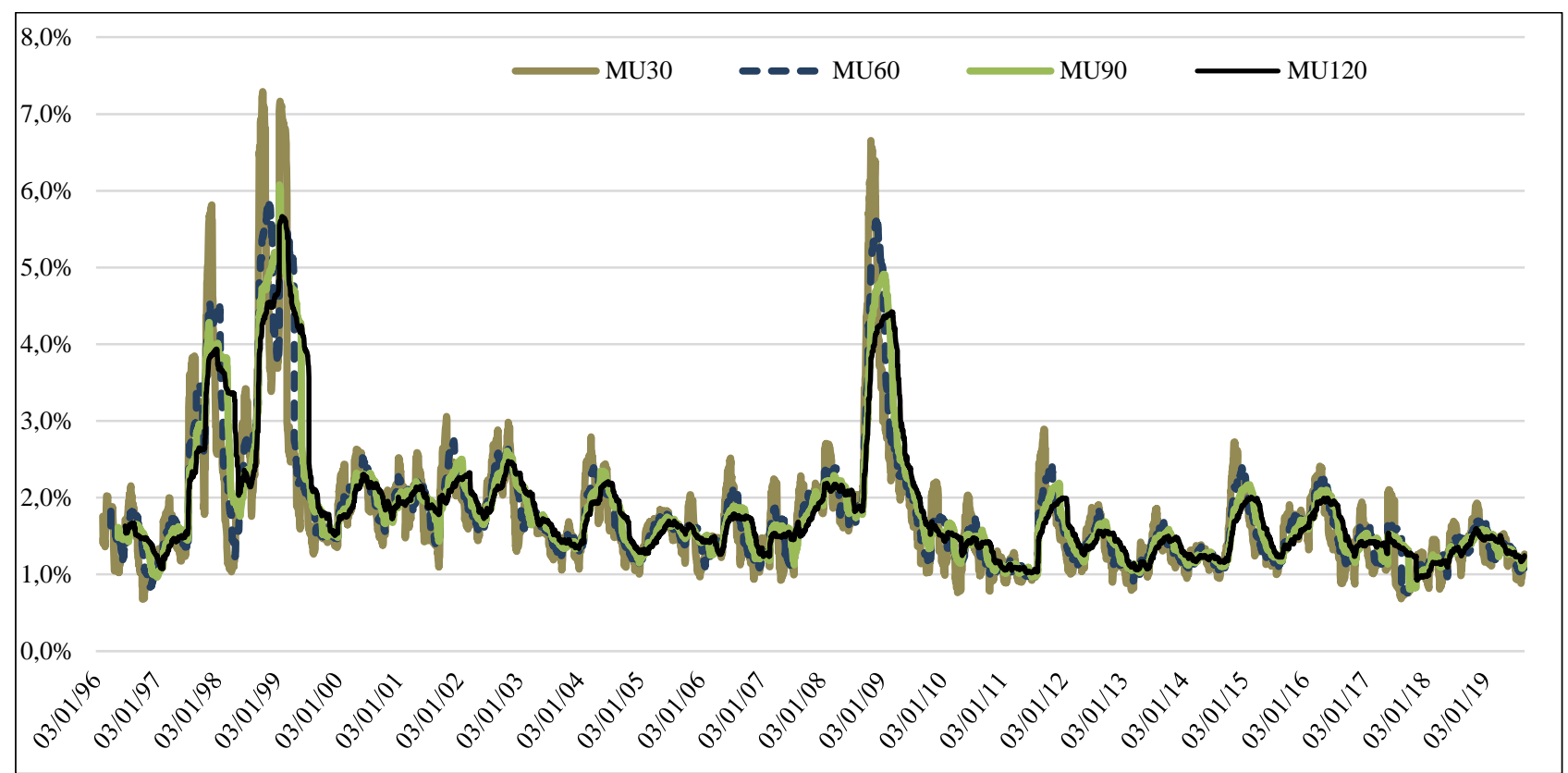

\subsection{Modelo empírico e variáveis de controle}

Para testar a relação entre incerteza de mercado (MU) e performance dos fundos de investimentos, desenvolveu-se modelo empírico controlado pelos efeitos que são apontados pela literatura como determinantes específicos do desempenho dos fundos de investimento, a saber: risco (Lambert, \& Platania, 2020; Racicot, \& Theoret , 2016), existência de taxa de performance (Dalmácio et al. 2008; Silva, Roma, \& Iquiapaza, 2018), possibilidade alavancagem (Yoshinaga et al. 2009) e tamanho do fundo (Borges, \& Materlanc, 2015; Castro, \& Minardi, 2009; Elton, Gruber, \& Blake, 2012). Para tanto, o seguinte modelo empírico foi estimado:

$$
\alpha_{i t}=\delta_{0}+\delta_{1} M U_{t}+\delta_{2} \operatorname{Risco}_{i t}+\delta_{3} \operatorname{TxPerf}_{i}+\delta_{4} \text { Alav }_{i}+\delta_{5} \text { Tamanho }_{i t}+\sum D A n o+\varepsilon_{i t}
$$


Onde,

$\alpha_{i t} \quad$ refere-se ao alfa de Jensen, medida de performance dos fundos, conforme estimado na Equação 1 para o fundo $i$ no mês $t$.

$M U_{t} \quad$ refere-se a medida de incerteza de mercado (market uncertainty) para o mês $t$.

Risco $_{i t}$ refere-se a medida de exposição ao risco sistemático do fundo $i$ no mês $t$ obtido por $\beta_{i t}$ conforme Equação 1 .

$\operatorname{TxPerf} f_{i}$ refere-se a variável dummy assumindo valor 1 caso o fundo possua taxa de performance destinada aos gestores, uma vez que o fundo superou seu benchmark e 0 caso contrário.

$\operatorname{Alav}_{i} \quad$ refere-se a variável dummy assumindo valor 1 caso o fundo opere de maneira alavancada e 0 caso contrário.

Tamanho $_{\text {it }}$ refere-se ao tamanho do fundo, definido como o ranqueamento do logaritmo natural do patrimônio líquido do fundo Tamanho $_{i t}=(\operatorname{RankPL}-1) /(N-1)$. Onde RankPL é o ranking do tamanho do patrimônio líquido do fundo $i$ em relação aos demais fundos da amostra no mês $t$, e $\mathrm{N}$ é o número de fundos com informações naquele mês. Desta forma, todos os fundos são classificados em uma escala de 0 a 1 de acordo com o tamanho relativo aos demais fundos da amostra.

DAno refere-se a variável dummy para cada ano analisado visando capturar eventuais efeitos sistêmicos específicos não associados a incerteza de mercado (tal como ambiente político).

A Equação 2, como apresentada, busca identificar uma possível relação sistêmica entre o desempenho dos fundos de investimento e a incerteza de mercado por meio do coeficiente $\delta_{1}$. No entanto, ela não responde se os efeitos da incerteza afetam de maneira homogênea fundos de diferentes características, em especial em função de tamanho e perfil de risco. Para tanto, utilizou variáveis integrativas para se avaliar diferenças incrementais/marginais do impacto da incerteza em fundos de acordo com tamanho e exposição ao risco sistemático. Assim,

$$
\begin{gathered}
\alpha_{i t}=\delta_{0}+\delta_{1} M U_{t}+\delta_{2} \text { Risco }_{i t}+\delta_{3} \text { Tamanho }_{i t}+\delta_{4} M U_{t} * \text { Risco }_{i t}+\delta_{5} M U_{t} * \text { Tamanho }_{i t} \\
+\delta_{6} \text { TxPerf }_{i}+\delta_{7} \text { Alav }_{i}+\sum \text { DAno }+\varepsilon_{i t}
\end{gathered}
$$

Com isso, os coeficientes $\delta_{4}$ e $\delta_{5}$ mostram o efeito relativo da incerteza de mercado para fundos de acordo com o tamanho e perfil de risco distintos. Assim, coeficiente $\delta_{4}$ positivo e significante indicaria que fundos maiores possuem performance superior aos fundos menores em momentos de maiores incertezas e, da mesma forma, $\delta_{5}$ positivo e significante indicaria que fundos com perfil de risco mais agressivos possuem performance superior aos menos expostos em momentos de maiores incertezas.

As Equações 2 e 3 foram estimadas por meio de regressões OLS com correções dos erros para heterocedasticidade (estimação robusta) conforme White (1980).

\section{RESULTADOS EMPÍRICOS}

\subsection{Apresentação e descrição dos dados}

A Tabela 1 mostra a estatística descritiva da amostra de fundos utilizada e das principais variáveis contínuas deste estudo. Em média, o valor dos fundos é de $\mathrm{R} \$ 117,4$ milhões sendo que há grande dispersão de tamanho, principalmente por alguns poucos fundos de ações muito grandes (outliers da amostra), daí a diferença significativa entre o valor médio e mediano dos fundos. 
Considerando todas as observações (todos os fundos ao longo de todo o período), o retorno nominal médio foi de $0,9 \%$ ao mês, porém, quando analisado o excesso de retorno sobre a taxa livre de risco (CDI), conforme Equação 1, verifica-se que o retorno médio é bem mais modesto, de 0,03\% ao mês; medianas também seguem tendência similar.

Após a estimação da Equação 1, os valores distribucionais de alfa de Jensen e beta calculados para os 1.243 fundos são também apresentados na Tabela 1. Percebe-se que, em geral, os fundos apresentaram performance incremental (superior) de $0,09 \%$ ao mês em relação ao portfólio de mercado (Ibovespa), porém, uma parcela significativa de fundos (45\% das observações) apresentou performance inferior ao portfólio de mercado (alfas negativos). Como era de se esperar, a quase totalidade dos fundos de ações possui risco sistemático (beta) inferior ao portfólio de mercado, isso se deve ao fato de que, apesar de investirem majoritariamente em ações, muitos fundos possuem parcela significativa de seus ativos alocados em títulos de renda fixa para atender a critérios de liquidez ou de variação de estratégias. Assim, em média, os fundos possuem coeficientes betas de 0,7453 , indicando que possuem volatilidade inferior à média de mercado, tal tendência ocorre para a maior parte da amostra (mais de $75 \%$ das observações apresentam betas inferiores a um).

Tabela 1 - Estatísticas descritivas e distribucional das variáveis de interesse

\begin{tabular}{|c|c|c|c|c|c|c|c|}
\hline & $\begin{array}{r}\text { Tamanho } \\
(\mathrm{R} \$ \mathrm{Mi})\end{array}$ & $\begin{array}{r}\text { Retorno Nominal } \\
\text { Mensal }\end{array}$ & $\begin{array}{r}\text { Retorno } \\
\text { Mensal em } \\
\text { Excesso } \\
(\text { Ri-Rf }) \\
\end{array}$ & $\begin{array}{l}\text { Alpha } \\
\alpha_{i t}\end{array}$ & $\beta_{i t}^{\text {Beta }}$ & $\begin{array}{r}\text { Incerteza } \\
\text { de } \\
\text { Mercado } \\
\text { (30 dias) }\end{array}$ & $\begin{array}{r}\text { Incerteza } \\
\text { de } \\
\text { Mercado } \\
\text { (120 dias) } \\
\end{array}$ \\
\hline Média & 117,4 & $0,90 \%$ & $0,03 \%$ & $0,09 \%$ & 0,7253 & 0,0177 & 0,0183 \\
\hline Desvio padrão & 262,5 & $6,43 \%$ & $6,43 \%$ & $0,97 \%$ & 0,2957 & 0,0091 & 0,0079 \\
\hline Mínimo & 0,0 & $-50,41 \%$ & $-51,71 \%$ & $-10,56 \%$ & $-0,5533$ & 0,0068 & 0,0093 \\
\hline $5 \%$ & 2,4 & $-8,64 \%$ & $-9,57 \%$ & $-1,13 \%$ & 0,2744 & 0,0096 & 0,0112 \\
\hline $25 \%$ & 13,3 & $-2,24 \%$ & $-3,11 \%$ & $-0,26 \%$ & 0,5468 & 0,0124 & 0,0138 \\
\hline $50 \%$ & 42,0 & $0,88 \%$ & $0,06 \%$ & $0,07 \%$ & 0,7416 & 0,0156 & 0,0158 \\
\hline $75 \%$ & 113,8 & $4,41 \%$ & $3,54 \%$ & $0,48 \%$ & 0,9288 & 0,0200 & 0,0200 \\
\hline $95 \%$ & 470,3 & $10,12 \%$ & $9,21 \%$ & $1,36 \%$ & 1,0622 & 0,0318 & 0,0392 \\
\hline Máximo & 9245,9 & $63,75 \%$ & $62,68 \%$ & $18,07 \%$ & 4,5573 & 0,0729 & 0,0567 \\
\hline Observações (N) & 125.066 & 123.833 & 123.833 & 109.939 & 109.939 & 255 & 255 \\
\hline
\end{tabular}

Apresentação da distribucional das variáveis de interesse para os 1.243 fundos no período de 1996 a 2019, totalizando 125.066 observações não balanceadas. Retorno mensal é calculado com base no logaritmo natural da divisão da cota do fundo $i$ no mês $t$ pela cota em $t$-1. Retorno mensal em excesso é a diferença entre o retorno do fundo $i$ no mês $t$ e o retorno do portfólio de mercado (Ibovespa) no mesmo período. Alfa $\left(\alpha_{i t}\right)$ refere-se alfa de Jensen calculado conforme Equação 1 em um período móvel de 24 meses para um fundo $i$ no mês $t$. Beta $\left(\beta_{i t}\right)$ refere-se a medida de exposição ao risco sistemático do fundo $i$ no mês $t$ obtido por conforme Equação 1. Incerteza de mercado (MU - market uncertainty) para o mês $t$, calculado pelo desvio padrão dos retornos diários em quatro abordagens variando de 30 a 120 dias precedentes ao encerramento do mês $t$. Por questões de limitação de espaço e brevidade, apenas as medidas extremas para 30 e 120 dias são apresentadas.

As estimações do alfa de Jensen foram realizadas para cada um dos 1.243 fundos da amostra com base na Equação 1 em relação aos diversos períodos, possibilitando que a medida de desempenho variasse ao longo do tempo. O Gráfico 2 apresenta o comportamento temporal dessa medida de performance de forma agregada a partir da apuração da mediana do alfa dos fundos para cada um dos meses e da média ponderada de acordo com o tamanho (patrimônio líquido) de cada fundo.

Gráfico 2 - Comportamento da mediana e média ponderado por tamanho do parâmetro temporal de perfomance $\left(\alpha_{t}\right)$ estimado conforme Eq.1 


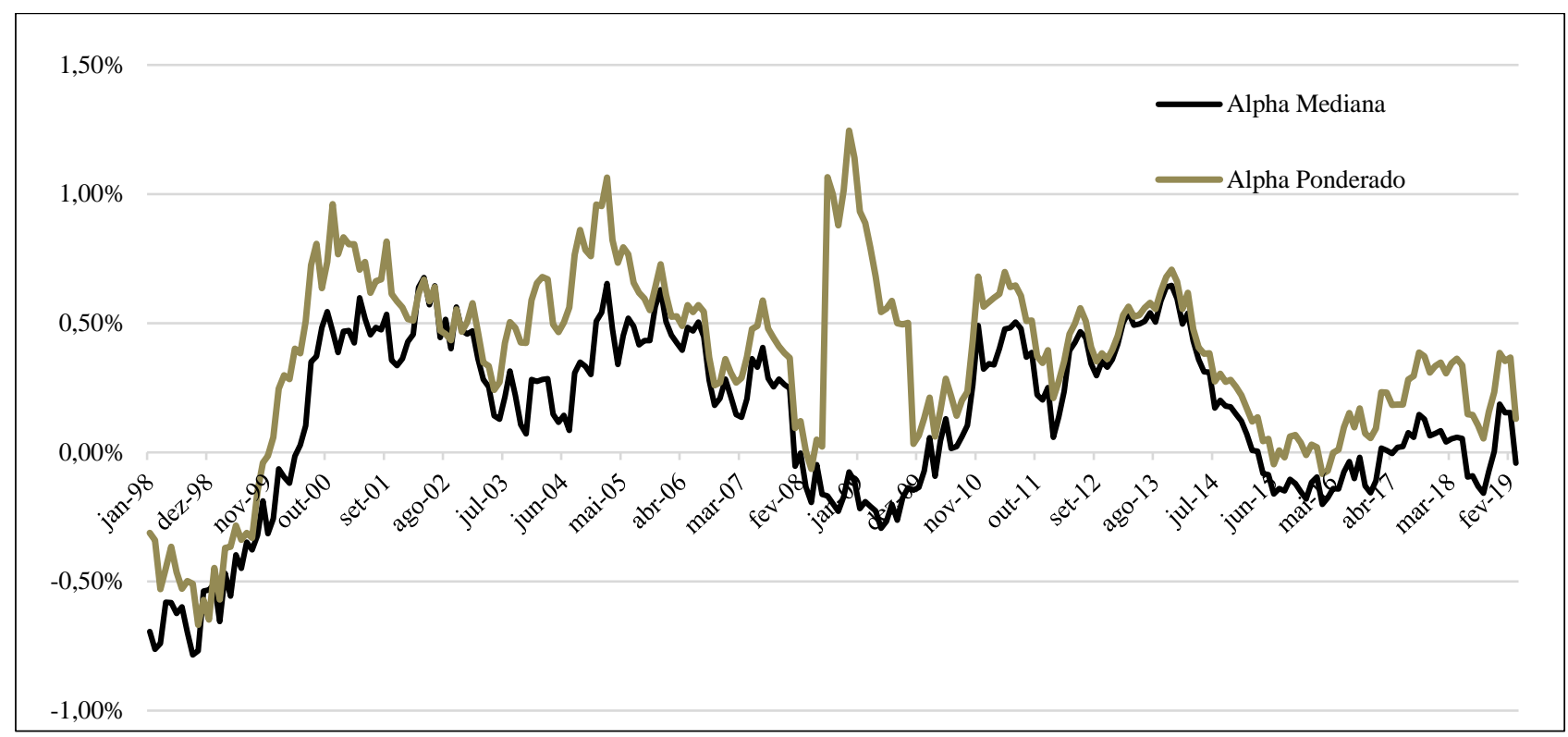

Como pode se perceber, ao longo do período analisado, há mudanças significativas na performance agregada dos fundos. Havendo, inclusive, variações entre performances positivas e negativas dos fundos em relação ao benchmark de mercado (Ibovespa). Em geral, o alfa ponderado apresenta níveis superiores de performance que a mediana (especialmente durante a crise financeira internacional de 2008). Isso pode ser explicado pelo fato de que, ao se ponderar o coeficiente, há maior relevância de fundos maiores na apuração do índice agregado o que sugere, de imediato, uma grande relevância do tamanho do fundo na definição de sua performance. Ou seja, a performance está associada ao tamanho do fundo, o que será avaliado nas próximas seções.

\subsection{Relação entre performance e incerteza de mercado}

Para testar a hipótese de associação entre e performance do fundo e incerteza de mercado (MU), estimou-se a Equação 2. Os resultados das estimações são apresentados na Tabela 2 considerando a amostra total de fundos. Adicionalmente, a estimação da Equação 2 foi realizada para a amostra dividida em quatro portfólios de acordo com os quartis de tamanho médio do fundo, uma vez que a análise distribucional anterior sugere forte efeito do tamanho na explicação do desempenho.

Os resultados apresentados na Tabela 2 sugerem fortemente relação negativa entre performance e incerteza de mercado $\left(\delta_{1}<0\right.$ e significativo), ou seja, períodos com maiores incertezas estão associados a períodos de menores performance dos fundos. Tal evidência corrobora as ideias de que a incerteza de mercado pode estar associada à redução da capacidade dos agentes do mercado em estimar a performance futura das empresas (Amiram et al, 2018; Hope, \& Kang, 2005), afetando a formulação de estratégias de alocação de recursos e dificultando a previsão de movimentos macroeconômicos (Jurado, Ludvigson, \& Ng, 2015), bem como concentrando a negociação de ativos com menores níveis de retorno (Racicot, \& Theoret, 2016). Cabe notar que esse resultado já é incremental e relativo ao portfólio de mercado (Ibovespa), ou seja, em períodos de maior incerteza, os gestores de fundos têm, em média, performance relativa inferior ao benchmark do mercado.

Os resultados reforçam a literatura anterior que identificou efeitos positivos e significativos do tamanho do fundo, sugerindo que maiores fundos contam com maiores performances, potencialmente derivadas de maiores habilidades dos gestores em gerar performance superior (Borges, \& Materlanc, 2015; Castro, \& Minardi, 2009), gerando maiores ganhos de escala e, 
possivelmente, acesso diferenciado a um maior grau de informações (Elton, Gruber, \& Blake, 2012).

Diferentemente do que se possa imaginar, para a amostra completa, a exposição ao risco sistemático do fundo possui relação negativa com performance, sugerindo que, em média, fundos que assumem maior risco (maior volatilidade relativa ao mercado) possuem desempenhos inferiores a fundos menos arriscados. Tal evidência corrobora os achados de prêmio de risco de mercado negativo documentado por Gonçalves Junior et al. (2011) no mercado brasileiro.

Tabela 2 - Relação entre performance do fundo e incerteza de mercado (Eq. 2)

\begin{tabular}{|c|c|c|c|c|c|c|c|c|c|c|}
\hline \multirow[b]{2}{*}{ Intercepto $\left(\delta_{0}\right)$} & \multicolumn{2}{|c|}{$\begin{array}{l}\text { Amostra } \\
\text { Total }\end{array}$} & \multicolumn{2}{|c|}{$\begin{array}{l}\text { Fundos Pequenos } \\
\text { (25\% inferiores) }\end{array}$} & \multicolumn{2}{|c|}{$\begin{array}{l}\text { Médios- } \\
\text { pequenos }\end{array}$} & \multicolumn{2}{|c|}{$\begin{array}{l}\text { Médios- } \\
\text { grandes }\end{array}$} & \multicolumn{2}{|c|}{$\begin{array}{l}\text { Fundos Grandes } \\
\text { (25\% superiores) }\end{array}$} \\
\hline & $\begin{array}{l}-0,004 \\
(-5,22)\end{array}$ & **** & $\begin{array}{l}-0,007 \\
(-6,72)\end{array}$ & $* * *$ & $\begin{array}{l}0,001 \\
(0,71)\end{array}$ & & $\begin{array}{l}0,007 \\
(7,27)\end{array}$ & $* * * *$ & $\begin{array}{l}-0,005 \\
(-2,74)\end{array}$ & $* * * *$ \\
\hline$M U\left(\delta_{1}\right)$ & $\begin{array}{l}-0,099 \\
(-10,12)\end{array}$ & $* * *$ & $\begin{array}{l}-0,129 \\
(-8,71)\end{array}$ & $* * *$ & $\begin{array}{l}-0,106 \\
(-8,22)\end{array}$ & $* * *$ & $\begin{array}{l}-0,094 \\
(-7,97)\end{array}$ & $* * *$ & $\begin{array}{l}-0,071 \\
(-2,35)\end{array}$ & $* *$ \\
\hline $\operatorname{Risco}\left(\delta_{2}\right)$ & $\begin{array}{l}-0,005 \\
(-9,54)\end{array}$ & $* * *$ & $\begin{array}{l}-0,001 \\
(-1,49)\end{array}$ & & $\begin{array}{c}-0,009 \\
(-14,01)\end{array}$ & $* * *$ & $\begin{array}{l}-0,008 \\
(-13,96)\end{array}$ & $* * *$ & $\begin{array}{l}0,000 \\
(0,01)\end{array}$ & \\
\hline$T x P e f\left(\delta_{3}\right)$ & $\begin{array}{c}0,006 \\
(44,29)\end{array}$ & $* *$ & $\begin{array}{l}0,000 \\
(2,59)\end{array}$ & $* * *$ & $\begin{array}{l}0,000 \\
(1,95)\end{array}$ & $* *$ & $\begin{array}{c}0,001 \\
(15,23)\end{array}$ & $* * *$ & $\begin{array}{l}0,000 \\
(2,92)\end{array}$ & *** \\
\hline $\operatorname{Alav}\left(\delta_{4}\right)$ & $\begin{array}{l}0,001 \\
(9,60)\end{array}$ & $* * *$ & $\begin{array}{l}0,001 \\
(6,18)\end{array}$ & $* * *$ & $\begin{array}{l}-0,001 \\
(-5,06)\end{array}$ & $* * *$ & $\begin{array}{l}0,001 \\
(9,13)\end{array}$ & $* * *$ & $\begin{array}{l}0,002 \\
(5,43)\end{array}$ & $* * *$ \\
\hline Tamanho $\left(\delta_{5}\right)$ & $\begin{array}{l}0,001 \\
(7,16) \\
\end{array}$ & ${ }^{* * * *}$ & & & & & & & & \\
\hline Controle de tempo & $\operatorname{sim}$ & & $\operatorname{sim}$ & & $\operatorname{sim}$ & & $\operatorname{sim}$ & & $\operatorname{sim}$ & \\
\hline F-Stat & 622,87 & $* * *$ & 107,5 & $* * *$ & 162,05 & $* * *$ & 176,43 & $* * *$ & 205,79 & **** \\
\hline $\mathrm{R}^{2}$ & 0,1471 & & 0,0972 & & 0,1802 & & 0,1936 & & 0,1002 & \\
\hline $\operatorname{Obs}(\mathrm{N})$ & 109.799 & & 26.034 & & 26.620 & & 29.036 & & 28.352 & \\
\hline
\end{tabular}

A variável dependente, performance do fundo, refere-se alfa de Jensen $\left(\alpha_{i t}\right)$ calculado conforme Equação 1 em um período móvel de 24 meses para um fundo $i$ no mês $t$. $M U_{t}$ é a medida de incerteza de mercado (market uncertainty) para o mês $t$, calculado pelo desvio padrão dos retornos diários nos 60 dias precedentes ao encerramento do mês $t$. Risco $i t$ é a medida de exposição ao risco sistemático do fundo $i$ no mês $t$ obtido por $\beta_{i t}$ conforme Equação 1 . TxPerf $f_{i}$ é uma variável dummy assumindo valor 1 caso o fundo possua taxa de performance destinada aos gestores caso o fundo supere seu benchmark e 0 caso contrário. lav $_{i}$ é uma variável dummy assumindo valor 1 caso o fundo opere de maneira alavancada e 0 caso contrário. Tamanho ${ }_{i t}$ refere-se ao tamanho do fundo, definido como o ranqueamento do logaritmo do logaritmo natural do patrimônio líquido do fundo Tamanho $_{i t}=(\operatorname{RankPL}-1) /(N-1)$. Onde RankPL é o ranking do tamanho do patrimônio líquido do fundo $i$ em relação aos demais fundos da amostra no mês $t$, e $\mathrm{N}$ é o número de fundos com informações naquele mês. Desta forma, todos os fundos são classificados em uma escala de 0 a 1 de acordo com o tamanho relativo aos demais fundos da amostra. Coeficientes das variáveis dummy para controle temporal foram omitidas da apresentação por limitação de espaço e brevidade na apresentação. Estatísticas $t$ são apresentadas em parênteses. ***, ** e * indicam relações estatisticamente significativas ao nível de $1 \%, 5 \%$ e $10 \%$, respectivamente.

A Tabela 2 também apresenta os resultados estimados para os portfólios de fundos divididos de acordo com seus tamanhos médios. A relação com incerteza de mercado $\left(\delta_{1}\right)$ se mantém negativa e significativa para todos os portfólios de tamanho dos fundos, porém, há uma redução sistemática do coeficiente para fundos maiores. Ou seja, a relação negativa da incerteza de mercado tende a ser mais relevante na redução da performance para fundos menores. Isso novamente indica que o porte do fundo é capaz de trazer maiores retornos aos cotistas (Borges, \& Materlanc, 2015; Castro, \& Minardi, 2009; Elton, Gruber, \& Blake, 2012), inclusive em períodos de maior incerteza 
econômica. Para as regressões com portfólios de tamanho, os demais coeficientes de controle seguem o comportamento verificado na análise da amostra geral.

A fim de se verificar o efeito incremental/relativo de tamanho e perfil de risco na relação entre performance e incerteza de mercado, estimou-se a Equação 3 e os resultados são apresentados na Tabela 3. Além da estimativa de incerteza de mercado baseada no desvio padrão dos retornos diários no intervalo de 90 dias (MU90), como análise de sensibilidade, a Tabela 3 apresenta os resultados para as demais definições de incerteza com base em 30 (MU30), 60 (MU60) e 120 (MU120) dias.

Os resultados mostram consistência entre os coeficientes estimados anteriormente e entre as diversas definições de incerteza para a relação entre performance do fundo e incerteza de mercado $\left(\delta_{1}\right)$, ou seja, há relação negativa e significativa entre incerteza de mercado. Demais relações e conclusões acerca da relação do tamanho do fundo (relação positiva e significativa) e do perfil de risco (relação negativa e significativa) se mantiveram inalteradas em relação aos resultados anteriores e as demais medidas de incerteza de mercado.

Tabela 3 - Relação entre performance do fundo e incerteza de mercado incremental em função de tamanho e perfil de risco (Eq. 3)

\begin{tabular}{|c|c|c|c|c|c|}
\hline & MU30 & MU60 & MU90 & & $M U 120$ \\
\hline \multirow[t]{2}{*}{ Intercepto $\left(\delta_{0}\right)$} & 0,000 & 0,002 & 0,003 & & 0,004 \\
\hline & 0,13 & 1,04 & 1,36 & & 1,48 \\
\hline \multirow[t]{2}{*}{$M U\left(\delta_{1}\right)$} & $-0,452^{* * *}$ & $-0,529^{* * *}$ & $-0,559$ & $* * *$ & $-0,576^{* * *}$ \\
\hline & $-2,95$ & $-3,16$ & $-3,19$ & & $-3,11$ \\
\hline \multirow[t]{2}{*}{$\operatorname{Risco}\left(\delta_{2}\right)$} & $-0,010^{* * *}$ & $-0,011^{* * *}$ & $-0,011$ & $* * *$ & $-0,012^{* * *}$ \\
\hline & $-4,40$ & $-4,31$ & $-4,25$ & & $-4,09$ \\
\hline \multirow[t]{2}{*}{$\operatorname{Tamanho}\left(\delta_{3}\right)$} & $0,005^{* * *}$ & $0,005^{* * *}$ & 0,005 & $* * *$ & $0,005^{* * *}$ \\
\hline & 8,94 & 7,67 & 7,47 & & 7,83 \\
\hline \multirow[t]{2}{*}{$M U^{*}$ Tamanho $\left(\delta_{4}\right)$} & $0,114^{* * * *}$ & $0,119^{* * *}$ & 0,117 & $* * *$ & $0,101^{* *}$ \\
\hline & 3,07 & 2,90 & 2,80 & & 2,41 \\
\hline \multirow[t]{2}{*}{$M U^{*} \operatorname{Risco}\left(\delta_{5}\right)$} & $0,386^{* *}$ & $0,443^{* *}$ & 0,462 & $* *$ & $0,473^{* *}$ \\
\hline & 2,21 & 2,35 & 2,35 & & 2,30 \\
\hline \multirow[t]{2}{*}{$\operatorname{TxPef}\left(\delta_{6}\right)$} & $0,001^{* * *}$ & $0,001^{* * *}$ & 0,001 & $* * *$ & $0,001^{* * *}$ \\
\hline & 9,47 & 9,44 & 9,38 & & 9,35 \\
\hline \multirow[t]{2}{*}{$\operatorname{Alav}\left(\delta_{7}\right)$} & $0,001^{* * *}$ & $0,001^{* * *}$ & 0,001 & $* * *$ & $0,001^{* * *}$ \\
\hline & 7,49 & 7,48 & 7,51 & & 7,55 \\
\hline Controle de tempo & $\operatorname{sim}$ & $\operatorname{sim}$ & $\operatorname{sim}$ & & $\operatorname{sim}$ \\
\hline F-Stat & $586,14^{* * *}$ & $588,98^{* * *}$ & 590,27 & $* * *$ & $592,22^{* * *}$ \\
\hline $\mathrm{R}^{2}$ & 0,1523 & 0,1533 & 0,153 & & 0,1524 \\
\hline $\operatorname{Obs}(\mathrm{N})$ & 109.799 & 109.799 & 109.799 & & 109.799 \\
\hline
\end{tabular}

A variável dependente performance do fundo, refere-se alfa de Jensen $\left(\alpha_{i t}\right)$ calculado conforme Equação 1 em um período móvel de 24 meses para um fundo $i$ no mês $t$. $M U_{t}$ é a medida de incerteza de mercado (market uncertainty) para o mês $t$, calculado pelo desvio padrão dos retornos diários nos 30,60, 90 e 120 dias precedentes ao encerramento do mês $t$. Risco $o_{i t}$ é a medida de exposição ao risco sistemático do fundo $i$ no mês $t$ obtido por $\beta_{i t}$ conforme Equação 1 . TxPerf $f_{i}$ é uma variável dummy assumindo valor 1 caso o fundo possua taxa de performance destinada aos gestores caso o fundo supere seu benchmark e 0 caso contrário. Alav ${ }_{i}$ é uma variável dummy assumindo valor 1 caso o fundo opere de maneira alavancada e 0 caso contrário. Tamanho $_{i t}$ refere-se ao tamanho do fundo, definido como o ranqueamento do logaritmo natural do patrimônio líquido do fundo Tamanho $_{i t}=(\operatorname{RankPL}-1) /(N-1)$. Onde RankPL é o ranking do tamanho do patrimônio líquido do fundo $i$ em relação aos demais fundos da amostra no mês $t$, e $\mathrm{N}$ é o número de fundos com informações naquele mês. Desta forma, todos os fundos são classificados em uma escala de 0 a 1 de acordo com o tamanho relativo aos demais fundos da amostra. Coeficientes das variáveis dummy para controle temporal foram omitidos da apresentação por limitação de espaço e brevidade na apresentação. Estatísticas $t$ são apresentadas em parênteses. ***, ** $\mathrm{e} *$ indicam relações estatisticamente significativas ao nível de $1 \%, 5 \%$ e $10 \%$, respectivamente. 
No que diz respeito ao efeito relativo da incerteza de mercado para fundos de acordo com o tamanho $\left(\delta_{4}\right)$ e perfil de risco $\left(\delta_{5}\right)$ verificam-se coeficientes positivos e significativos. Ou seja, fundos maiores possuem performance superior aos fundos menores em momentos de maiores incertezas e fundos com perfil de risco mais agressivos possuem performance superior aos menos expostos em momentos de maiores incertezas, respectivamente.

De maneira geral, em linha com Amiram et al. (2018) e Hope e Kang (2005), os resultados mostram que a incerteza de mercado pode afetar a formulação de estratégias de alocação de recursos e dificultando a previsão de movimentos macroeconômicos. Assim, os resultados neste artigo documentam uma relação negativa e estatisticamente significativa entre performance dos fundos e incerteza de mercado indicando a aceitação da primeira hipótese de pesquisa. Ou seja, períodos com maiores incertezas de mercado estão associados a menores performance dos fundos sugerindo que em períodos de maior incerteza, gestores tendem a concentrando a negociação de ativos com menores níveis de retorno (Racicot, \& Theoret, 2016). Tal relação é consistente entre as diversas estimações e abordagens apresentadas neste artigo.

Como resultados adicionais, também se verificou de forma consistente que, em média, o tamanho do fundo de investimento, a existência de taxa de performance pelo gestor e a utilização de estratégias alavancadas de investimento estão positivamente associados com a performance dos fundos. Resultados também indicam, em média, uma relação negativa e significativa entre o desempenho e o perfil de risco, sugerindo que apesar de gestores a concentrarem a negociação de ativos com menores níveis de retorno frente as incerteza de mercado (Racicot, \& Theoret, 2016), fundos que mantem um perfil . Ao mesmo tempo em que tal resultado é intrigante, pois confronta a bem aceita relação positiva entre risco e retorno e o presente artigo apresenta argumentos para tal evidência, a relação negativa não é totalmente consistente, especialmente em função do tamanho dos fundos.

Este artigo também documenta uma relação incremental, positiva e significativa entre tamanho do fundo e perfil de risco na relação entre performance e incerteza de mercado, sugerindo aceitação da segunda e da terceira hipótese desta pesquisa. Ou seja, fundos maiores possuem performance superior aos fundos menores em momentos de maiores incertezas, sugerindo maior habilidade dos gestores (Borges, \& Materlanc, 2015) e maiores condições potenciais de ganho de escala nas negociações (Elton, Gruber, \& Blake, 2012). Finalmente, como sugere Racicot e Theoret (2016), períodos de maior incerteza estão associados a maior concentração da negociação de ativos com menores níveis de risco, e, consequentemente, de menores retornos. No entanto, o presente estudo documenta que fundos que mantem perfil de risco elevando durante momentos de incerteza tendem a obter, em média, performance superior aos menos expostos a riscos.

\subsection{Testes Adicionais e de Robustez}

Visando expandir e reforçar os resultados documentados neste artigo, foram realizadas análises e estimações adicionais e de robustez. Primeiramente, apesar de o índice alfa do CAPM ser amplamente difundido na literatura e considerado como a principal media de performance por sua melhor explicação do retorno dos fundos (Agarwal, Green, \& Ren, 2018), foram realizados testes adicionais incluindo os retornos em excesso (ou anormais) e retornos absolutos realizados (Varga, 2001) dos fundos de investimento como medida alternativa de performance, conforme apresentado na Tabela 1. Sendo que os retornos em excesso (ou anormais) são representados pelo retorno superior ou inferior em relação ao índice de mercado (Ibovespa no caso). Os resultados mantiveram qualitativamente os mesmos para a Equação 2 em termos de sinal e significância estatística, os resultados para o retorno anormal estão evidenciados na Tabela 4. Já os resultados para a Equação 3 mostram que o coeficiente de interesse (incerteza de mercado) deixaram de ser estatisticamente significantes para retornos anormal e absoluto. Os resultados para o retorno absoluto não foram reportados por limitação de espaço, mas ficam à disposição mediante solicitação aos autores. 
Tabela 4 - Testes adicionais: Retorno como medida de performance, estimação por efeitos fixos e com variáveis instrumentais

\begin{tabular}{|c|c|c|c|c|c|c|}
\hline & \multicolumn{2}{|c|}{$\begin{array}{c}\text { Retorno Anormal como } \\
\text { Variável de Performance dos } \\
\text { Fundos }\end{array}$} & \multicolumn{2}{|c|}{$\begin{array}{l}\text { Estimação por } \\
\text { Efeitos Fixos }\end{array}$} & \multicolumn{2}{|c|}{$\begin{array}{l}\text { Estimaçãocom Variáveis } \\
\text { Instrumentais (IV) }\end{array}$} \\
\hline & Eq. 2 & Eq. 3 & Eq. 2 & Eq. 3 & 2SLS & GMM \\
\hline \multirow[t]{2}{*}{ Intercepto } & $-0.043^{* * *}$ & $-0.066^{* * *}$ & $-0.004^{* * *}$ & $0.004^{* * *}$ & $0.004^{* * *}$ & $0.005^{* * *}$ \\
\hline & $(-5.08)$ & $(-5.31)$ & $(-8.75)$ & $(9.38)$ & $(22.02)$ & $(35.330)$ \\
\hline \multirow[t]{2}{*}{$M U$} & $-0.408^{* * *}$ & 1.214 & $-0.108^{* * *}$ & $-0.636^{* * *}$ & $-0.189^{* * * *}$ & $-0.229^{* * *}$ \\
\hline & $(-5.78)$ & (1.61) & $(-20.34)$ & $(-43.20)$ & $(-16.35)$ & $(-25.37)$ \\
\hline \multirow[t]{2}{*}{ Risco } & $-0.003^{*}$ & $0.025^{*}$ & $0.001^{* * *}$ & $-0.006^{* * *}$ & & \\
\hline & $(-1.79)$ & $(1.88)$ & $(9.13)$ & $(-24.09)$ & & \\
\hline \multirow[t]{2}{*}{ Tamanho } & $0.006^{* * *}$ & $0.007^{* *}$ & $0.006^{* * *}$ & $0.002^{* * *}$ & & \\
\hline & (7.92) & $(2.06)$ & $(32.12)$ & $(5.87)$ & & \\
\hline \multirow[t]{2}{*}{$M U^{*}$ Tamanho } & & -0.072 & & $0.239^{* * *}$ & & \\
\hline & & $(-0.32)$ & & $(16.30)$ & & \\
\hline \multirow[t]{2}{*}{$M U^{*}$ Risco } & & $-1.915^{* *}$ & & $0.484^{* * *}$ & & \\
\hline & & $(-1.98)$ & & $(35.72)$ & & \\
\hline \multirow[t]{2}{*}{ TxPef } & $0.001^{*}$ & $0.001^{*}$ & & & & \\
\hline & $(1.91)$ & $(1.76)$ & & & & \\
\hline \multirow[t]{2}{*}{ Alav } & 0.001 & $0.001^{*}$ & & & & \\
\hline & $(1.46)$ & $(1.91)$ & & & & \\
\hline Efeitos fixos & & & $\operatorname{sim}$ & $\operatorname{sim}$ & & \\
\hline Hausman $\left(\chi^{2}\right)$ & & & $195.36^{* * *}$ & $143.240^{* * *}$ & & \\
\hline Chow F-test & & & $42.72^{* * *}$ & $43.590^{* * *}$ & & \\
\hline Controle de tempo & $\operatorname{sim}$ & $\operatorname{sim}$ & $\operatorname{sim}$ & $\operatorname{sim}$ & $\operatorname{sim}$ & $\operatorname{sim}$ \\
\hline F-test / Wald $\chi^{2}$ & $364.02^{* * *}$ & $338.47^{* * *}$ & $803.82^{* * *}$ & $811.2^{* * *}$ & $267.18^{* * *}$ & $643.89^{* * *}$ \\
\hline $\mathrm{R}^{2}$ & 0.0828 & 0.0853 & 0.1011 & 0.1077 & - & - \\
\hline $\operatorname{Obs}(\mathrm{N})$ & 109,799 & 109,799 & 109,799 & 109,799 & 109,799 & 109,799 \\
\hline
\end{tabular}

Nas duas primeira colunas, a variável dependente refere-se ao retorno anormal como medida alternativa de performance do fundo. Nas quatro últimas colunas, refere-se alfa de Jensen $\left(\alpha_{i t}\right)$ calculado conforme Equação 1 em um período móvel de 24 meses para um fundo $i$ no mês $t$. $M U_{t}$ é a medida de incerteza de mercado (market uncertainty) para o mês $t$, calculado pelo desvio padrão dos retornos diários nos 60 dias precedentes ao encerramento do mês $t$. Demais variáveis seguem as definições anteriores. Estatísticas dos coeficientes são apresentadas em parênteses. ***, ** e * indicam relações estatisticamente significativas ao nível de $1 \%, 5 \%$ e $10 \%$, respectivamente.

Uma segunda abordagem foi de realizar modelagem dos modelos empíricos por meio de dados em painel com efeitos fixos e aleatórios. Os modelos de efeitos fixos buscam controlar aspectos individuais dos fundos e que não variam ao longo do tempo. Como as regressões anteriores possuem controles de taxa de performance e a utilização de operações com alavancagem, que são elementos invariantes no tempo, ao utilizar painel com efeitos fixos, naturalmente perde-se tais controles, ao mesmo tempo em que se adicional controles que englobam outros itens invariantes no tempo Também foram estimados os modelos por meio de efeitos aleatórios, porém, teste diagnóstico de Hausman indica quenão é possível rejeitar a hipótese nula de que os estimadores sob efeito fixo e efeito aleatório são idênticos. Assim, as diferenças dos coeficientes são sistemáticas, sugerindo que as estimativas dos efeitos fixos podem ser mais consistentes e eficazes do que o modelo de efeitos aleatórios (Baltagi, 2005). Adicionalmente, o teste (F) de Chow para 
agrupamento (poolability) rejeitou a hipótese nula de igualdade dos coeficientes aos níveis de significância usuais, validando a preferência pelo uso do modelo de efeitos fixos. No entanto, em ambas as estimações, por efeitos fixos e aleatórios, os resultados são altamente convergentes e qualitativamente os mesmos dos resultados já apresentados com nas regressões anteriores. A Tabela 4 reporta tais resultados com estimação de efeitos fixos para as Equações 2 e 3 e sugere a confirmação de relação negativa e significante entre performance do fundo e incerteza de mercado.

Finalmente, foram analisados potenciais fontes de endogeneidade nas relações analisadas. A natureza endógena da relação entre desempenho dos fundos e condições de mercado é plausível, particularmente, em razão de serem essas duas variáveis correlacionadas com outras variáveis não observáveis, pode tornar difícil estabelecer relações de causa e efeito, representando um desafio para a literatura sobre em finanças (Barros et al., 2020). Tipicamente, estudos anteriores têm buscado superar problemas de endogeneidade, por exemplo, por meio da inclusão de variáveis instrumentais e uso de equações simultâneas (Aguiar, \& Pimentel, 2017). Nesse sentido, foram realizadas regressões utilizando a variável de performance (alpha) defasada como variável instrumental (método agrupado e por efeitos fixos, não reportados por limitação de espaço) e regressões agrupadas com variáveis instrumentais, com estimação pelo método dos mínimos quadrados de dois estágios (2SLS) e dos momentos generalizados (GMM), utilizando as variáveis tamanho, risco, existência de taxa de performance e de operações alavancadas à variável incerteza de mercado (instrumentalizada).

Estimação com variáveis instrumentais pelos métodos 2SLS, que se baseia na utilização de uma variável z que tenha alta correlação com a variável endógena, mas não com o erro (Silva, Roma, \& Iquiapaza, 2020) e GMM que permite o uso eficiente de defasagens apropriadas dos regressores potencialmente endógenos como suas próprias variáveis instrumentais (Silveira et al, 2010). Utilizando de suposições de exogeneidade sequencial dos regressores, modelos GMM "apresentam-se como alternativas capazes de contornar eficazmente todos os problemas" de endogeneidade (Barros et al., 2020, p. 437). Os resultados das estimações 2SLS e GMM estão apresentados na Tabela 4 e mostram, em ambas as estimações com variáveis instrumentalizadas, coeficientes negativos e significantes, sugerindo a confirmação da relação negativa e significante entre performance dos fundos e incerteza de mercado.

Conforme argumentam Barros et al. (2020, p. 439) "uma solução para o problema da endogeneidade dinâmica é o uso de determinadas defasagens (e/ou diferenças temporais) dos regressores originais como variáveis instrumentais", nesse sentido, como mencionado, também foram utilizadas regressões OLS utilizando a variável de performance (alpha) defasada como variável instrumental com método agrupado e por efeitos fixos. Os resultados, não reportados por limitação de espaço, se mantiveram no sentido de confirmar a relação negativa e significante.

Em todos os testes adicionais realizados, não foram encontradas evidências de que as relações documentadas neste artigo estejam substancialmente enviesadas a ponto de inviabilizar as conclusões finais. No entanto, como todo estudo empírico, os resultados são válidos para o período e amostra analisados, bem como, os resultados se mantiveram sob as abordagens metodológicas descritas, podendo ser mantidos ou refutados a partir de abordagens distintas, o que abre caminho para mais testes e análises empíricas que complementem o conhecimento científico corrente.

\section{CONCLUSÕES}

Este artigo analisa a relação entre performance dos fundos de investimento em ações e incerteza de mercado (market uncertainty). Diferentemente da literatura anterior, o presente estudo assume que a performance dos fundos de investimento varia ao longo do tempo e busca-se explicar tais variações a questões associadas a incerteza de mercado. Para tanto, utiliza-se uma amostra representativa e abrangente compreendendo 1.243 fundos, no período de janeiro de 1996 a março de 2019, resultando em 125.066 observações iniciais. Para avaliação da performance dos fundos de 
investimento, utiliza-se a medida de alfa de Jensen, amplamente utilizada na literatura da área, de acordo com o modelo CAPM.

De maneira geral, os resultados neste artigo documentam uma relação negativa e estatisticamente significativa entre performance dos fundos e incerteza de mercado, ou seja, períodos de maior incerteza estão associados a menores performance dos fundos, sugerindo aceitação da primeira hipótese de pesquisa. Tais achados sugerem que a incerteza de mercado pode impossibilitar aos gestores a alocação ótima de recursos e a antecipação dos movimentos macroeconômicos (Jurado, Ludvigson, \& Ng, 2015) uma vez que é capaz de reduzir a capacidade dos agentes do mercado em estimar a performance futura das empresas (Amiram et al, 2018; Hope, \& Kang, 2005) e podem fazer com que gestores concentrem a negociação de ativos de menor risco e, portanto, com menores níveis de retorno (Racicot, \& Theoret, 2016), justificando a relação negativa entre as variáveis.

Tal relação é consistente entre as diversas estimações e abordagens apresentadas neste artigo. Como resultados adicionais, também se verificou que, em média, o tamanho do fundo de investimento, a existência de taxa de performance pelo gestor e a utilização de estratégias alavancadas de investimento estão positivamente associados com a performance dos fundos.

Também são documentas relações incrementais, positivas e significativas entre tamanho do fundo e perfil de risco na associação entre performance e incerteza de mercado. Ou seja, fundos maiores possuem performance superior aos fundos menores em momentos de maiores incertezas e fundos com perfil de risco mais agressivos possuem performance superior aos menos expostos em momentos de maiores incertezas, respectivamente

Os resultados também documentam uma relação incremental, positiva e significativa entre tamanho do fundo e perfil de risco na relação entre performance e incerteza de mercado, sugerindo aceitação da segunda e da terceira hipótese desta pesquisa. Por um lado, fundos maiores possuem performance superior aos fundos menores em momentos de maiores incertezas, sugerindo maior habilidade dos gestores (Borges, \& Materlanc, 2015) e maiores condições potenciais de ganho de escala nas negociações (Elton, Gruber, \& Blake, 2012). Por outro, Racicot e Theoret (2016) sugere que períodos de maior incerteza estão associados a maior concentração da negociação em ativos com menores níveis de risco, e, consequentemente, de menores retornos, nesse sentido, o presente estudo documenta que fundos que mantem perfil de risco elevando durante momentos de incerteza tendem a obter, em média, performance superior aos menos expostos a riscos.

Este artigo busca contribuir para a literatura ao explicar a variação da performance dos fundos de investimento em ações com base na incerteza de mercado de cada período. Os resultados são, portanto, potencialmente úteis a profissionais (como investidores, gestores de recursos, analistas de investimento e reguladores) e acadêmicos (que amplamente analisaram o tema sem, no entanto, analisar o desempenho de fundos como uma função temporal da incerteza de mercado). Do ponto de vista prático, este artigo colabora com processo de tomada de decisão de investidores ao evidenciar elementos de desempenho dos fundos associados a incerteza de mercado e como tal aspecto afeta o reconhecimento do desempenho real de empresas na montagem de carteiras de fundos.

Tais resultados são substancialmente relevantes em mercados emergentes como é o caso do Brasil, em que o ambiente macroeconômico é caracterizado por grandes níveis de incerteza quando comparados a mercados menos voláteis. Nesse sentido, cabe notar que os resultados são válidos para o período e amostra analisados, bem como sob a metodologia empregada. Ainda que esforços tenham sido empregados para limitar interpretações enviesadas, os resultados podem variar em função de outras abordagens.

\section{REFERÊNCIAS}

Agarwal, V., Green, T. C., \& Ren, H. (2018). Alpha or beta in the eye of the beholder: What drives hedge fund flows?. Journal of Financial Economics, 127(3), 417-434. 
Aguiar, A. B. D., \& Pimentel, R. C. (2017). Remuneração de executivos e desempenho no mercado brasileiro: relações contemporâneas e defasadas. Revista de Administração Contemporânea, 21(4), 545-568.

Amiram, D., Landsman, W. R., Owens, E., \& Stubben, S. (2017). How are analysts' forecasts affected by high uncertainty?. Journal of Business Finance \& Accounting, 45(3-4), 295-318.

Bali, T. G., Brown, S. J., \& Caglayan, M. O. (2014). Macroeconomic risk and hedge fund returns. Journal of Financial Economics, 114(1), 1-19.

Baltagi, B. H. (2005). Econometric analysis of panel data. 3rd Edition Hoboken, NJ: John Wiley \& Sons.

Barros, L. A., Bergmann, D. R., Castro, F. H., \& Silveira, A. D. M. D. (2020). Endogeneidade em regressões com dados em painel: Um guia metodológico para pesquisa em finanças corporativas. Revista Brasileira de Gestão de Negócios, 22(SPE), 437-461.

Billio, M., Getmansky Sherman, M., \& Pelizzon, L. (2010). Crises and hedge fund risk. University Ca'Foscari of Venice, Dept. of Economics Research Paper Series, (10-08), 07-14.

Borges, E. C., \& Martelanc, R. (2015). Sorte ou habilidade: uma avaliação dos fundos de investimento no Brasil. Revista de Administração, 50(2), 196-207.

Boyson, N. M., Stahel, C. W., \& Stulz, R. M. (2010). Hedge fund contagion and liquidity shocks. The Journal of Finance, 65(5), 1789-1816.

Cai, B., Cheng, T., \& Yan, C. (2018). Time-varying skills (versus luck) in US active mutual funds and hedge funds. Journal of Empirical Finance, 49, 81-106.

Cao, C., Simin, T. T., \& Wang, Y. (2013). Do mutual fund managers time market liquidity?. Journal of Financial Markets, 16(2), 279-307.

Casaccia, M. C., Galli, O. C., de Macêdo, G. R., \& Leitao, C. (2011). Análise do desempenho de fundos de investimentos: um estudo em ações brasileiras no período de janeiro de 2004 a agosto de 2009. Revista Organizações em Contexto, 7(13), 1-30.

Castro, B. R., \& Minardi, A. M. A. F. (2009). Comparação do desempenho dos Fundos de Ações Ativos e Passivos. Revista Brasileira de Finanças, 7(2).

Ceretta, P. S., \& da Costa Jr, N. C. (2001). Avaliação e seleção de fundos de investimento: um enfoque sobre múltiplos atributos. Revista de Administração Contemporânea, 5(1), 7-22.

Ceretta, P. S., \& Milani, B. (2012). Tamanho e rentabilidade dos fundos brasileiros de investimento em ações. Revista Alcance, 19(4), 461-475.

Chen, Y., \& Liang, B. (2007). Do market timing hedge funds time the market?. Journal of Financial and Quantitative Analysis, 42(4), 827-856.

Comissão de Valores Mobiliários. (2014). Fundos de Investimento, Cadernos CVM, 3.

Comissão de Valores Mobiliários. (2014). Instrução CVM n ${ }^{o}$ 555, de 17 de dezembro de 2014.

Costa, L. S., Blank, F. F., Oliveira, F. L. C., \& Villalobos, C. E. M. (2019). Modelo de precificação condicional com heteroscedasticidade: Avaliação de fundos brasileiros. RAE-Revista de Administração de Empresas, 59(4), 225-241.

Dalmácio, F. Z., Nossa, V., \& Zanquetto Filho, H. (2008). Avaliação da relação entre a performance e a taxa de administração dos fundos de ações ativos brasileiros. Revista de Educação e Pesquisa em Contabilidade, 1(3), 1-20.

Duanmu, J., Malakhov, A., \& McCumber, W. R. (2017). Beta active hedge fund management. Journal of Financial and Quantitative Analysis, 53(6), 2525-2558.

Eid Jr., W., \& Rochman, R. R. (2008, May). Fundos de Investimento Ativos e Passivos no Brasil: Comparando e Determinando os seus Desempenhos. In VII Encontro Brasileiro de Finanças. Sociedade Brasileira de Finanças. 
Elton, E. J., Gruber, M. J., \& Blake, C. R. (2012). Does mutual fund size matter? The relationship between size and performance. The Review of Asset Pricing Studies, 2(1), 31-55.

Faria, G. H., de Souza, K. G., \& Malaquias, R. F. (2016). Análise do desempenho dos fundos de investimentos brasileiros de gestão ativa e gestão passiva. Revista da Faculdade de Administração e Economia, 8(1), 138-161.

Ferson, W. E., \& Schadt, R. W. (1996). Measuring fund strategy and performance in changing economic conditions. The Journal of Finance, 51(2), 425-461.

Fung, W., Hsieh, D. A., Naik, N. Y., \& Ramadorai, T. (2008). Hedge funds: Performance, risk, and capital formation. The Journal of Finance, 63(4), 1777-1803.

Gârleanu, N., \& Pedersen, L. H. (2018). Efficiently inefficient markets for assets and asset management. The Journal of Finance, 73(4), 1663-1712.

Gomes, F. A. R., \& Cresto, V. (2010). Avaliação do desempenho dos fundos long-short no Brasil. Revista Brasileira de Finanças, 8(4), 505-529.

Gonçalves Junior, W., Rochman, R. R., Eid Junior, W., \& Chalela, L. R. (2011). Estimating the Brazilian market premium. Revista de Administração Contemporânea, 15(5), 931-954.

Guzella, M. D. S., \& Campani, C. H. (2017). Poder preditivo do desempenho de fundos brasileiros de ações a partir do R2 como medida do grau de seletividade. Revista Contabilidade \& Finanças, 28(74), 282296.

Harvey, C. R., \& Liu, Y. (2019). Cross-sectional alpha dispersion and performance evaluation. Journal of Financial Economics, 134(2), 273-296.

Hope, O. K., \& Kang, T. (2005). The association between macroeconomic uncertainty and analysts' forecast accuracy. Journal of International Accounting Research, 4(1), 23.

Jensen, M. C. (1969). Risk, the pricing of capital assets, and the evaluation of investment portfolios. The Journal of Business, 42(2), 167-247.

Jurado, K., Ludvigson, S. C., \& Ng, S. (2015). Measuring uncertainty. American Economic Review, 105(3), 1177-1216.

Kosowski, R. (2011). Do mutual funds perform when it matters most to investors? US mutual fund performance and risk in recessions and expansions. The Quarterly Journal of Finance, 1(03), 607-664.

Lambert, M., \& Platania, F. (2020). The macroeconomic drivers in hedge fund beta management. Economic Modelling, 91, 65-80.

Malacrida, M. J. C., Yamamoto, M. M., Lima, G. A. S. F., \& Pimentel, R. C. (2007). Gestão ativa dos fundos de investimento: uma análise de desempenho. In Anais do $7^{\circ}$ Congresso USP de Controladoria e Contabilidade.

Malaquias, R. F., \& Junior, W. E. (2013). Market efficiency and performance of multimarket funds. Brazilian Review of Finance, 11(1), 119-142.

Matos, P. R. F., \& Nave, A. Fundos de investimento em ações no Brasil: performance e expertise de gestão. Brazilian Business Review, 9 (Especial), 1-38.

Otten, R., \& Bams, D. (2004). How to measure mutual fund performance: economic versus statistical relevance. Accounting \& Finance, 44(2), 203-222.

Paulo, W., \& Itosu, L. Y. (2012). Análise da Correlação entre a Taxa de Performance e o Desempenho de Fundos de Investimentos Multimercados. Revista de Finanças Aplicadas, 1, 14.

Racicot, F. É., \& Théoret, R. (2016). Macroeconomic shocks, forward-looking dynamics, and the behavior of hedge funds. Journal of Banking \& Finance, 62, 41-61. 
Rochman, R. R., \& Eid Jr, W. (2006). Fundos de investimento ativos e passivos no Brasil: comparando e determinando os seus desempenhos. Anais do EnANPAD. Associação Nacional dos Programas de PósGraduação e Pesquisa em Administração.

Silva, S. E., da Silva Roma, C. M., \& Iquiapaza, R. A. (2020). Turnover da carteira e o desempenho de fundos de investimentos em ações no Brasil. Revista de Contabilidade e Finanças, 31(83), 332-347.

Silva, S. E., Roma, C. M., \& Iquiapaza, R. A. (2018). A taxa de administração sinaliza o desempenho dos fundos de investimento em ações no Brasil?. Revista de Educação e Pesquisa Em Contabilidade $(\mathrm{REPeC}), 12(3)$.

Silveira, A. D. M., Leal, R. P. C., Silva, A. L. C, \& Barros, L. A. B. D. C. (2010). Endogeneity of Brazilian corporate governance quality determinants. Corporate Governance: The International Journal of Business in Society, 9(2), 191-202.

Sun, Z., Wang, A., \& Zheng, L. (2016). Only winners in tough times repeat: Hedge fund performance persistence over different market conditions. Journal of Financial and Quantitative Analysis, 53(5), 2199-2225

Varga, G. (2001). Índice de Sharpe e outros indicadores de performance aplicados a fundos de ações brasileiros. Revista de Administração Contemporânea, 5(3), 215-245.

White, H. (1980). A heteroskedasticity-consistent covariance matrix estimator and a direct test for heteroskedasticity. Econometrica, 48(4), 817-838.

Yoshinaga, C. E., Castro Jr, F., Lucchesi, E., \& Oda, A. (2009). Análise de estilo em fundos multimercados com e sem alavancagem no Brasil. REGES: Revista Eletrônica de Gestão, 2(1), 9-21.

Zheng, Y., Osmer, E., \& Zhang, R. (2018). Sentiment hedging: How hedge funds adjust their exposure to market sentiment. Journal of Banking \& Finance, 88, 147-160. 